\title{
Outcome of cardiac surgery in patients with low preoperative ejection fraction
}

\author{
Marina Pieri ${ }^{1}$, Alessandro Belletti ${ }^{1}$, Fabrizio Monaco ${ }^{1}$, Antonio Pisano ${ }^{2}$, Mario Musu ${ }^{3}$, Veronica Dalessandro', \\ Giacomo Monti', Gabriele Finco ${ }^{3}$, Alberto Zangrillo ${ }^{1,4}$ and Giovanni Landoni ${ }^{*}$
}

\begin{abstract}
Background: In patients undergoing cardiac surgery, a reduced preoperative left ventricular ejection fraction (LVEF) is common and is associated with a worse outcome. Available outcome data for these patients address specific surgical procedures, mainly coronary artery bypass graft (CABG). Aim of our study was to investigate perioperative outcome of surgery on patients with low pre-operative LVEF undergoing a broad range of cardiac surgical procedures.
\end{abstract}

Methods: Data from patients with pre-operative LVEF $\leq 40 \%$ undergoing cardiac surgery at a university hospital were reviewed and analyzed. A subgroup analysis on patients with pre-operative LVEF $\leq 30 \%$ was also performed.

Results: A total of 7313 patients underwent cardiac surgery during the study period. Out of these, 781 patients $(11 \%)$ had a pre-operative LVEF $\leq 40 \%$ and were included in the analysis. Mean pre-operative LVEF was $33.9 \pm 6$. $1 \%$ and in 290 patients (37\%) LVEF was $\leq 30 \%$. The most frequently performed operation was CABG (31\% of procedures), followed by mitral valve surgery (22\%) and aortic valve surgery $(19 \%)$. Overall perioperative mortality was $5.6 \%$. Mitral valve surgery was more frequent among patients who did not survive, while survivors underwent more frequently CABG. Post-operative myocardial infarction occurred in 19 (2.4\%) of patients, low cardiac output syndrome in 271 (35\%). Acute kidney injury occurred in 195 (25\%) of patients. Duration of mechanical ventilation was 18 (12-48) hours. Incidence of complications was higher in patients with LVEF $\leq 30 \%$. Stepwise multivariate analysis identified chronic obstructive pulmonary disease, pre-operative insertion of intra-aortic balloon pump, and pre-operative need for inotropes as independent predictors of mortality among patients with LVEF $\leq 40 \%$.

Conclusions: We confirmed that patients with low pre-operative LVEF undergoing cardiac surgery are at higher risk of post-operative complications. Cardiac surgery can be performed with acceptable mortality rates; however, mitral valve surgery, was found to be associated with higher mortality rates in this population. Accurate selection of patients, risk/benefit evaluation, and planning of surgical and anesthesiological management are mandatory to improve outcome.

Keywords: Cardiac surgery, Left ventricular dysfunction, Low cardiac output syndrome, Mitral valve surgery, Left ventricular ejection fraction, Coronary artery bypass graft, Intensive care, Anesthesia, Mortality

\footnotetext{
* Correspondence: landoni.giovanni@hsr.it

'Department of Anesthesia and Intensive Care, IRCCS San Raffaele Scientific Institute, Via Olgettina 60, 20132 Milan, Italy

Full list of author information is available at the end of the article
}

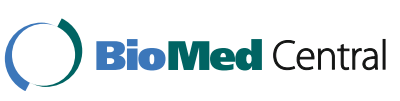

(C) 2016 The Author(s). Open Access This article is distributed under the terms of the Creative Commons Attribution 4.0 International License (http://creativecommons.org/licenses/by/4.0/), which permits unrestricted use, distribution, and reproduction in any medium, provided you give appropriate credit to the original author(s) and the source, provide a link to the Creative Commons license, and indicate if changes were made. The Creative Commons Public Domain Dedication waiver (http://creativecommons.org/publicdomain/zero/1.0/) applies to the data made available in this article, unless otherwise stated. 


\section{Background}

Low preoperative left ventricular ejection fraction (LVEF) is common in patients undergoing cardiac surgery, especially those scheduled for coronary artery bypass graft (CABG) surgery. Despite improvements in medical therapy and surgical techniques, management of patients with moderate or severe left ventricular dysfunction undergoing cardiac surgery remains challenging $[1,2]$. As known, patients with low LVEF are at a higher risk for postoperative complications and mortality after cardiac surgery [1]. Therefore, an early recognition of patients at risk for a worse outcome plays a pivotal role in the decision making process, allowing the prompt institution of an adequate support [3]. Several perioperative variables have been purposed as predictors of mortality [4-8], including acute renal failure [9] and pneumonia [10], and are currently applied in everyday clinical practice [10] to identify patients at higher risk. Low EF is per se the strongest predictor of a poor outcome and is included in all scoring system currently available. Indeed, low LVEF is associated to postoperative low cardiac output syndrome (LCOS), need for inotropic support $[11,12]$, acute renal failure [9, 13, 14], respiratory failure [1], pneumonia [10], atrial fibrillation [15], stroke, sepsis or endocarditis, deep sternal wound infection, bleeding requiring reoperation and gastrointestinal bleeding [1]. However, the outcome after cardiac surgery has improved over time leading to a significant decrease of the performance of the currently available scores. There is a currently unmet need for more sophisticated preoperative predictive parameters, which may help to further stratify patients with impaired cardiac function, that are nevertheless candidate to undergo cardiac surgery. Indeed several biological and procedural variables, the constant evolution in both practice of surgery and perioperative medicine, the volume of activity of the hospital should somehow be taken into consideration [16], together with EF.

Aim of the present study was therefore to assess the mortality rate in high-risk patients with low EF (<40\%) undergoing cardiac surgery and to identify the risk factors associated with a worse outcome in a national referral cardiac surgery center with a high volume of surgical activity.

\section{Methods}

The study was performed in accordance with the Declaration of Helsinki and its amendments. After approval by the local Ethical Committee (OSR Ethical Committee, 38 AN CCH 31-10-2013) data from all patients with LVEF $\leq$ $40 \%$ who underwent cardiac surgery at San Raffaele Scientific Institute over a 6 years' period were collected. No specific written consent was obtained for this retrospective observational study since all patients' data were anonymized and de-identified prior to analysis. However, all patients signed a written consent for the use of their data for scientific purposes.

All patients underwent transthoracic and/or transesophagel echocardiography as part of routine pre-operative assessment. The examination was performed by a cardiologist trained in perioperative echocardiography, usually the day before surgery. The threshold for data analysis (40 \%) followed the 2015 recommendation from the American Society of Echocardiography and the European Association of Cardiovascular Imaging [17], which further identified an LVEF value of $30 \%$ as the cut off of severely depressed cardiac function.

All patients underwent cardiac surgery under general anesthesia and at the end of the surgery were transferred to the intensive care unit (ICU). A standard premedication with morphine $0.1 \mathrm{mg} / \mathrm{kg}$ subcutaneously and scopolamine $0.25 \mathrm{mg}$ intramuscularly one hour before surgery was administered. General anesthesia was induced with an intravenous bolus of propofol, fentanyl and muscle relaxant and maintained with fentanyl, muscle relaxants and either halogenates or propofol (or both). An intravenous infusion of tranexamic acid was administered intraoperatively: $1 \mathrm{~g}$ in $20 \mathrm{~min}$ followed by a $400 \mathrm{mg} / \mathrm{h}$ infusion. A temperature of $32-34{ }^{\circ} \mathrm{C}$ was maintained during cardiopulmonary bypass $(\mathrm{CPB})$ and myocardial protection during aortic cross clamping was performed by anterograde and/or retrograde cold cardioplegia. Unfractionated heparin (at a starting dose of $3 \mathrm{mg} / \mathrm{kg}$ ) was administered in order to maintain an activated clotting time (ACT) of more than $480 \mathrm{~s}$ during CPB. Heparin was reversed with protamine in a 1:1 ratio. The target mean arterial pressure during $\mathrm{CPB}$ was $65 \mathrm{mmHg}$.

After surgery, patients were transferred to the ICU under sedation with propofol. Weaning from mechanical ventilation was started, in the absence of hemodynamic instability and major bleeding, as soon as normothermia and an adequate level of consciousness were achieved. Antibiotic prophylaxis was performed with intravenous cephazolin. Standard therapy also included hydration, antiacids and diuretics, as well as inotropic drugs and mechanical circulatory support devices when required by the hemodynamic conditions.

Myocardial infarction was defined according to the Consensus Conference for the Universal Definition of Myocardial Infarction [18]. Low cardiac output syndrome was defined as arterial hypotension (systolic blood pressure $<100 \mathrm{mmHg}$ ) with signs of organ hypoperfusion (decreased urine output, lactic acidosis,...) and cardiac index below $2 \mathrm{l} / \mathrm{min} / \mathrm{m}^{2}$ despite adequate fluid replacement. Cardiogenic shock was defined according to the IABP-SHOCK Trial [19]. Acute kidney injury (AKI) was diagnosed in the presence of an increase in 
serum creatinine of more than $50 \%$ or a decrease in the glomerular filtration rate (GFR) of more than $25 \%$ as compared to preoperative values [20]. The Cockroft-Gault equation was used to estimate GFR [21]. Age-CreatinineEjection Fraction (ACEF) score was calculated [22]. We defined "redo" a patient who had already undergone sternotomy for cardiac surgery. Postoperative atrial fibrillation (AF) was defined as a new onset of AF requiring pharmacological or electrical cardioversion during the ICU stay.

\section{Statistical analysis}

Data were stored electronically and analyzed using the 9.2 version of the SAS software (SAS Institute Inc., Cary, NC, USA). Categorical variables are reported as numbers (percent), whereas continuous variables are expressed as mean \pm standard deviation (SD) or as median (interquartile range) according to the Kolmogorov-Smirnov test. The Fisher's test was used to calculate $p$ values between two groups for categorical variables. Multiple logistic regression was used to identify independent predictors of mortality. A stepwise selection method was used for death (dichotomous variable), with COPD, Pre-operative intraaortic balloon pump (IABP), Pre-operative inotropes for patients with $\mathrm{FE} \leq 40 \%$ and with Preoperative renal failure and Mitral valve surgery for patients with $\mathrm{FE} \leq 30 \%$. The area under the ROC curves of the two predictive models was also calculated.

\section{Results}

Out of 7357 patients undergoing cardiac surgery in the study period, 7313 had data on preoperative LVEF. Of these, 781 patients (11\%) had preoperative LVEF $\leq 40 \%$ and were included in the study. Baseline characteristics, comorbidities, type of operation and intraoperative management of the study population are reported in Table 1.

Mean age was $65.4 \pm 10.3$ years, and $76 \%$ of patients were male. Mean preoperative LVEF was $33.9 \pm 6.1 \%$.

The most common intervention performed was CABG, followed by mitral valve surgery (either replacement or repair), and aortic valve replacement. Threehundred sixty six patients $(47 \%)$ underwent combined surgical procedures.

Postoperative outcomes are reported in Table 2 . Among patients with LVEF $\leq 40 \%$, mortality was $5.6 \%$ and was consistent with preoperative predictions (mean EuroSCORE was six and mean ACEF score was 5.59). Mortality rates for the different LVEF classes are presented in Fig. 1. As expected, mortality risk increases as LVEF decreases. In the study cohort, mitral valve surgery was the most common operation performed among non-survivors compared with survivors ( 32 vs. $22 \%, p=$ 0.009). Conversely, isolated CABG was the most common operation performed among survivors (16 vs. $5.4 \%$, $p=0.02$ ). Survivors had significantly shorter ICU length of stay (LOS) ( 3 vs. 12 days, $p<0.001$ ), hospital LOS ( 7 vs. 15.5 days, $p<0.001)$, duration of mechanical ventilation (18 vs. $88 \mathrm{~h}, p<0.001)$, lower need for renal replacement therapy (RRT) $(3.3 \%$ vs. $50 \%, p<0.001)$, lower troponin peak (7.83 vs. $21.32, p<0.001)$, and less need for blood transfusions (31 vs. $70 \%, p<0.001$ ). Regarding postoperative complications, patients who died had a significantly higher rate of LCOS (75 vs. $32 \%, p<0.001$ ), cardiogenic shock (55 vs. $3.4 \%, p<0.001$ ), AKI (86 vs. $21 \%, p<0.001$ ), sepsis (11 vs. $2.7 \%, p=0.01$ ), and severe pulmonary dysfunction ( 27 vs. $2.7 \%, p<0.001$ ).

Multivariate analysis identified the following independent predictors of mortality in patients with $\mathrm{LVEF} \leq 40 \%$ : history of chronic obstructive pulmonary disease (COPD) (odds ratio [OR] 3.419, $95 \%$ confidence interval [CI] 1.266-9.238, $p=0.015$ ), preoperative use of IABP (OR 3.335, $95 \%$ CI 1.258-8.839, $p=0.015$ ), and need for inotropes prior to surgery (OR 13.595, 95 \% CI $2.852-$ $64.808, p=0.001$ ) (Table 3). The area under the ROC curve was 0.61 .

Two hundred and ninety patients (37.13\%) had a preoperative LVEF below $30 \%$ (mean, $26.9 \pm 3.8 \%$ ). Baseline and outcomes data of these patients are shown as supplementary material (Additional file 1: Tables S1 and S2 respectively). Mean age $(65.4 \pm 9.9$ years $)$ was similar to the entire cohort with a prevalence of male.

Although the mortality rate in patients with LVEF $\leq$ $30 \%$ was higher $(7.6 \%)$ than the overall study population it was lower than expected (mean EuroSCORE $=7$; mean ACEF mortality risk $=10.19)$. One hundred-sixty patients (48\%) underwent combined surgery.

The most common operation performed in patients with $\mathrm{LVEF} \leq 30 \%$, who did not-survive was mitral valve surgery (37 \% of non-survivors vs. $21 \%$ of survivors, $p=$ $0.005)$. On the contrary, all the 59 patients $(12 \%)$ with LVEF $<30 \%$ who underwent isolated CABG survived. Unlike the whole cohort of low LVEF patients, in those with $\operatorname{LVEF} \leq 30 \%$ there was no statistically significant difference between survivors and non-survivors for the rate of wound infections, mediastinitis, sepsis, serum creatinine peak, hospital LOS, and length of mechanical ventilation. Moreover, no gastrointestinal complications occurred in this subgroup.

The rate of perioperative myocardial infarction was not statistically different between survivors and nonsurvivors, both in the entire study population and in the subgroup of patients with LVEF $\leq 30 \%$.

The only two predictors independently associated to mortality in the sub-group of patients with an EF $<30 \%$ were preoperative renal failure (defined as pre-operative eGFR $<90 \mathrm{~mL} / \mathrm{min}$ ) and mitral valve surgery (OR 6.845, $95 \%$ CI 1.841-25.45, $p=0.004$ and OR 5.244, $95 \%$ CI $1.290-21.322, p=0.021$, respectively) (Table 3 ). The area under the ROC curve was 0.53 . 
Table 1 Baseline and intra-operative characteristics of patients with ejection fraction $\leq 40 \%$ who underwent cardiac surgery: comparisons between survivors and dead patients

\begin{tabular}{|c|c|c|c|c|}
\hline Variable & Total $(N=781)$ & Survivors $(N=737)$ & Dead $(N=44)$ & $P$-value \\
\hline \multicolumn{5}{|l|}{ Preoperative characteristics } \\
\hline Gender (Male), $n$ & $597(76 \%)$ & $569(77 \%)$ & $28(64 \%)$ & 0.04 \\
\hline Age, years & $65.4 \pm 10.3$ & $65.3 \pm 10.4$ & $68.4 \pm 9.4$ & 0.0575 \\
\hline Height, cm & $169.6 \pm 8.1$ & $169.7 \pm 8.0$ & $167.6 \pm 9.4$ & 0.2 \\
\hline Weight, kg & $73.7 \pm 13.4$ & $73.8 \pm 13.3$ & $71.2 \pm 14.6$ & 0.2 \\
\hline BMI & $25.6 \pm 4.0$ & $25.6 \pm 4.0$ & $25.4 \pm 4.4$ & 0.8 \\
\hline \multicolumn{5}{|l|}{ Comorbidity } \\
\hline$>$ COPD,$n$ & $235(30 \%)$ & $210(28 \%)$ & $25(57 \%)$ & $<0.001$ \\
\hline$>$ Preoperative EF, \% & $33.9 \pm 6.1$ & $34.0 \pm 6.1$ & $31.8 \pm 6.0$ & 0.01 \\
\hline$>$ Preoperative $\mathrm{EF} \leq 40 \%, n$ & $781(100 \%)$ & & & \\
\hline$>$ Preoperative $\mathrm{EF} \leq 30 \%, n$ & $290(37 \%)$ & & & \\
\hline$>$ Peripheral vasculopathy, $n$ & $196(25 \%)$ & $183(25 \%)$ & $13(30 \%)$ & 0.5 \\
\hline$>$ Arterial hypertension, $n$ & $423(54 \%)$ & $402(55 \%)$ & $21(48 \%)$ & 0.4 \\
\hline$>$ Type II diabetes mellitus, $n$ & $159(20 \%)$ & $151(20 \%)$ & $8(18 \%)$ & 0.7 \\
\hline$>$ Carotid stenosis, $n$ & $71(9.1 \%)$ & $68(9.2 \%)$ & $3(6.8 \%)$ & 0.8 \\
\hline$>$ Angina, $n$ & $112(14 \%)$ & $104(14 \%)$ & $8(18 \%)$ & 0.5 \\
\hline$>$ Previous AMI, $n$ & $243(31 \%)$ & 227 (31 \%) & $16(36 \%)$ & 0.4 \\
\hline$>$ Previous TIA or stroke, $n$ & $61(7.8 \%)$ & $58(7.9 \%)$ & $3(6.8 \%)$ & 0.99 \\
\hline$>$ Previous vascular surgery, $n$ & $37(4.7 \%)$ & $37(5 \%)$ & $0(0 \%)$ & 0.3 \\
\hline$>$ Standard EuroSCORE & $6(4-8)$ & $6(4-8)$ & $8(6-10)$ & $<0.001$ \\
\hline$>$ ACEF score & $2.08(1.77-2.47)$ & $2.06(1.75-2.44)$ & $2.43(2.08-3.16)$ & $<0.001$ \\
\hline$>$ ACEF risk & $5.59(3.89-8.78)$ & $5.46(3.81-8.56)$ & $8.45(5.61-18.52)$ & $<0.001$ \\
\hline$>$ Endocarditis, $n$ & $22(2.8 \%)$ & $20(2.7 \%)$ & $2(4.5)$ & 0.4 \\
\hline$>$ Creatinine clearance, $\mathrm{ml} / \mathrm{h}$ & $65.1(49.2-82.6)$ & $65.67(50.23-83.33)$ & $49.1(39.66-69.27)$ & 0.002 \\
\hline$>$ Chronic renal failure, $n$ & 149 (19\%) & $134(18 \%)$ & $15(34 \%)$ & 0.009 \\
\hline > Dialysis, $n$ & $13(1.7 \%)$ & $12(1.6 \%)$ & $1(2.3 \%)$ & 0.5 \\
\hline NYHA & & & & 0.003 \\
\hline$>1$ & $51(6.5 \%)$ & $51(6.9 \%)$ & $0(0 \%)$ & \\
\hline$>\|$ & $208(27 \%)$ & $201(27 \%)$ & $7(16 \%)$ & \\
\hline$>111$ & $276(35 \%)$ & $267(36 \%)$ & $9(20 \%)$ & \\
\hline$>\mathrm{IV}$ & $43(5.5 \%)$ & $36(4.9 \%)$ & $7(16 \%)$ & \\
\hline Timing of surgery & & & & 0.2 \\
\hline$>$ Emergency, $n$ & $18(2.3 \%)$ & $16(2.2 \%)$ & $2(4.5 \%)$ & \\
\hline$>$ Urgency, $n$ & $129(17 \%)$ & 119 (16 \%) & $10(23 \%)$ & \\
\hline$>$ Election, $n$ & $634(81 \%)$ & $602(82 \%)$ & $32(73 \%)$ & \\
\hline Redo surgery, $n$ & $81(10 \%)$ & $73(9.9 \%)$ & $8(18 \%)$ & 0.08 \\
\hline Preoperative IABP, $n$ & $135(17 \%)$ & $121(16 \%)$ & $14(32 \%)$ & 0.009 \\
\hline Preoperative inotropes, $n$ & $17(2.2 \%)$ & $11(1.5 \%)$ & $6(14 \%)$ & $<0.001$ \\
\hline \multicolumn{5}{|l|}{ Chronic therapy } \\
\hline$>$ Antiplatelets, $n$ & 267 (34 \%) & $258(35 \%)$ & $9(20 \%)$ & 0.048 \\
\hline$>$ Diuretics, $n$ & $503(64 \%)$ & $470(64 \%)$ & $33(75 \%)$ & 0.13 \\
\hline > Beta-blockers, $n$ & $365(47 \%)$ & $353(48 \%)$ & $12(27 \%)$ & 0.008 \\
\hline$>$ Antibiotics, $n$ & $38(4.9 \%)$ & $34(4.6 \%)$ & $4(9.1 \%)$ & 0.16 \\
\hline
\end{tabular}


Table 1 Baseline and intra-operative characteristics of patients with ejection fraction $\leq 40 \%$ who underwent cardiac surgery: comparisons between survivors and dead patients (Continued)

\begin{tabular}{|c|c|c|c|c|}
\hline$>$ Calcium channel blockers, $n$ & $128(16 \%)$ & $121(16 \%)$ & $7(16 \%)$ & 0.9 \\
\hline$>$ Nitrates, $n$ & $217(28 \%)$ & $205(28 \%)$ & $12(27 \%)$ & 0.9 \\
\hline$>$ ACE inhibitors, $n$ & $496(64 \%)$ & $473(64 \%)$ & $23(52 \%)$ & 0.11 \\
\hline$>$ Oral anticoagulants, $n$ & $135(17 \%)$ & $130(18 \%)$ & $5(11 \%)$ & 0.4 \\
\hline$>$ Heparin, $n$ & $61(7.8 \%)$ & $57(7.7 \%)$ & $4(9.1 \%)$ & 0.8 \\
\hline Creatinine, mg/dl & $1.2 \pm 0.9$ & $1.2 \pm 0.9$ & $1.5 \pm 1.1$ & 0.004 \\
\hline Bilirubin, mg/dl & $0.8(0.57-1.1)$ & $0.8(0.57-1.04)$ & $0.94(0.63-1.4)$ & 0.1 \\
\hline \multicolumn{5}{|l|}{ Surgical interventions } \\
\hline CABG, $n$ & $390(31 \%)$ & $373(31 \%)$ & $17(23 \%)$ & 0.12 \\
\hline$>$ Isolated CABG, $n$ & 189 (15\%) & $185(16 \%)$ & $4(5.4 \%)$ & 0.02 \\
\hline Mitral valve surgery, $n$ & $282(22 \%)$ & $258(22 \%)$ & $24(32 \%)$ & 0.009 \\
\hline$>$ Isolated mitral valve surgery, $n$ & $90(7.1 \%)$ & $84(7.1 \%)$ & $6(8.1 \%)$ & 0.7 \\
\hline$>$ Mitral valve replacement, $n$ & $126(10 \%)$ & 117 (9.9\%) & $9(12 \%)$ & 0.4 \\
\hline$>$ Mitral valve repair, $n$ & $156(12 \%)$ & $141(12 \%)$ & $15(20 \%)$ & 0.02 \\
\hline Aortic valve surgery, $n$ & 241 (19\%) & $227(19 \%)$ & $14(19 \%)$ & 0.9 \\
\hline$>$ Isolated aortic valve surgery, $n$ & $81(6.4 \%)$ & $76(6.4 \%)$ & $5(6.8 \%)$ & 0.8 \\
\hline$>$ Aortic valve replacement, $n$ & $241(19 \%)$ & $227(19 \%)$ & $14(19 \%)$ & 0.9 \\
\hline$>$ Aortic valve repair, $n$ & $1(0.08 \%)$ & $1(0.08 \%)$ & $0(0 \%)$ & 0.99 \\
\hline Tricuspid valve surgery, $n$ & $96(7.6 \%)$ & $91(7.7 \%)$ & $5(6.8 \%)$ & 0.99 \\
\hline$>$ Isolated tricuspid valve surgery, $n$ & $3(0.24 \%)$ & $3(0.25 \%)$ & $0(0 \%)$ & 0.99 \\
\hline$>$ Tricuspid valve replacement, $n$ & $6(0.48 \%)$ & $6(0.51 \%)$ & $0(0 \%)$ & 0.99 \\
\hline$>$ Tricuspid valve repair, $n$ & $90(7.1 \%)$ & $85(7.2 \%)$ & $5(6.8 \%)$ & 0.99 \\
\hline Pulmonic valve surgery, $n$ & $1(0.08 \%)$ & $1(0.08 \%)$ & $0(0 \%)$ & 0.99 \\
\hline$>$ Isolated pulmonic valve surgery, $n$ & $1(0.08 \%)$ & $1(0.08 \%)$ & $0(0 \%)$ & 0.99 \\
\hline Surgery on ascending aorta, $n$ & $83(6.6 \%)$ & $76(6.4 \%)$ & $7(9.5 \%)$ & 0.2 \\
\hline$>$ Isolated surgery on ascending aorta, $n$ & $6(0.48 \%)$ & $6(0.51 \%)$ & $0(0 \%)$ & 0.99 \\
\hline Left ventricle surgery, $n$ & $77(6.1 \%)$ & $76(6.4 \%)$ & $1(1.4 \%)$ & 0.11 \\
\hline$>$ Isolated left ventricle surgery, $n$ & $12(0.95 \%)$ & $12(1 \%)$ & $0(0 \%)$ & 0.99 \\
\hline \multicolumn{5}{|l|}{ Intraoperative management } \\
\hline $\mathrm{CPB}, n$ & $696(91 \%)$ & $656(89 \%)$ & 40 (91\%) & 0.4 \\
\hline Duration of aortic cross clamping, min & $61(48-78)$ & $61(47-78)$ & $69.5(51-78)$ & 0.3 \\
\hline Duration of $\mathrm{CPB}$, min & $85(65-102)$ & $84(65-101)$ & $95(70-114)$ & 0.3 \\
\hline
\end{tabular}

$A C E F$ age-creatinine-ejection fraction, $A M I$ acute myocardial infarction, $B M I$ body mass index, $C A B G$ coronary artery bypass graft, COPD chronic obstructive pulmonary disease, CPB cardiopulmonary bypass, EF ejection fraction, IABP intra-aortic balloon pump, NYHA New York Heart Association, TIA transient ischemic attack

As mitral valve surgery was found to be associated with mortality, we performed a further comparison between patients who had undergone isolated mitral valve versus isolated CABG surgery. The mortality rate of patients with $\mathrm{EF} \leq 40 \%$ (Table 1) was not different between these two groups $(p=0.081)$, but reached statistical significance in patients with $\mathrm{EF} \leq 30 \%$ (Additional file 1: Table S1).

Baseline descriptive data of patients undergoing mitral valve surgery are reported in Additional file 1: Table S3.

\section{Discussion}

Data from this large cohort of cardiac surgical patients confirmed that low LVEF still represent a common issue in this setting, affecting more than $10 \%$ of patients. This population represents a group at higher surgical risk due to the greatly reduced cardiovascular reserve; for this reason, a comprehensive and insightful preoperative risk stratification, beyond the LVEF value itself, is strongly recommended. In this sense, our experience may add new clues to be implemented into clinical practice. 
Table 2 Post-operative complications and outcome data of patients with ejection $\leq 40 \%$ who underwent cardiac surgery: comparisons between survived and dead patients

\begin{tabular}{|c|c|c|c|c|}
\hline Variable & Total $(N=781)$ & Survived $(N=737)$ & Dead $(N=44)$ & $P$-value \\
\hline \multicolumn{5}{|l|}{ Post-operative complications } \\
\hline Post-operative AMI, $n$ & $19(2.4 \%)$ & $17(2.3 \%)$ & $2(4.5 \%)$ & 0.3 \\
\hline Post-operative peak troponin value, $\mathrm{ng} / \mathrm{ml}$ & $8.03(4.4-15)$ & $7.83(4.3-14.35)$ & $21.32(8.07-29.73)$ & $<0.001$ \\
\hline Post-operative AF, $n$ & $202(26 \%)$ & $191(26 \%)$ & $11(25 \%)$ & 0.9 \\
\hline LCOS, n & $271(35 \%)$ & $238(32 \%)$ & $33(75 \%)$ & $<0.001$ \\
\hline Inotropes more than $48 \mathrm{~h}, n$ & $233(30 \%)$ & $204(28 \%)$ & $29(66 \%)$ & $<0.001$ \\
\hline Cardiogenic shock, $n$ & $49(6.3 \%)$ & $25(3.4 \%)$ & $24(55 \%)$ & $<0.001$ \\
\hline Post-operative peak creatinine value, mg/dl & $1.3 \pm 0.9$ & $1.3 \pm 0.9$ & $1.5 \pm 1.1$ & 0.004 \\
\hline $\mathrm{AKI}, n$ & $195(25 \%)$ & $157(21 \%)$ & $38(86 \%)$ & $<0.001$ \\
\hline RRT, $n$ & $46(5.9 \%)$ & $24(3.3 \%)$ & $22(50 \%)$ & $<0.001$ \\
\hline Bleeding in the first 12 postoperative hours, $\mathrm{ml}$ & $280(200-400)$ & $280(200-400)$ & $260(180-425)$ & 0.9 \\
\hline Total post-operative bleeding, ml & $460(300-720)$ & $460(300-720)$ & $585(455-735)$ & 0.2 \\
\hline Need for blood products transfusion, $n$ & $263(34 \%)$ & $232(31 \%)$ & $31(70 \%)$ & $<0.001$ \\
\hline RBC transfusions, $n$ of units per patient & $0(0-1)$ & $0(0-1)$ & $3(0-6.5)$ & $<0.001$ \\
\hline FFP transfusions, $\mathrm{n}$ of units per patient & $0(0-0)$ & $0(0-0)$ & $0(0-3)$ & $<0.001$ \\
\hline PLT transfusions, $n$ of units per patient & $0(0-0)$ & $0(0-0)$ & $0(0-0.5)$ & $<0.001$ \\
\hline Neurological damage type $1, n$ & $16(2 \%)$ & $14(1.9 \%)$ & $2(4.5 \%)$ & 0.2 \\
\hline Neurological damage type $2, n$ & $22(2.8 \%)$ & $19(2.6 \%)$ & $3(6.8 \%)$ & 0.12 \\
\hline Severe pulmonary dysfunction, $n$ & $32(4.1 \%)$ & $20(2.7 \%)$ & $12(27 \%)$ & $<0.001$ \\
\hline Tracheostomy, $n$ & $27(3.5 \%)$ & $12(1.6 \%)$ & $15(34 \%)$ & $<0.001$ \\
\hline Need for re-intubation, $n$ & $23(2.9 \%)$ & $13(1.8 \%)$ & $10(23 \%)$ & $<0.001$ \\
\hline Sepsis, $n$ & $25(3.2 \%)$ & $20(2.7 \%)$ & $5(11 \%)$ & 0.01 \\
\hline Mediastinitis, $n$ & $6(0.77 \%)$ & $3(0.41 \%)$ & $3(6.8 \%)$ & 0.003 \\
\hline \multicolumn{5}{|l|}{ Outcome data } \\
\hline Duration of MV, hours & $18(12-48)$ & $18(12-43)$ & $88(34-288)$ & $<0.001$ \\
\hline ICU stay, days & $3(1-5)$ & $3(1-5)$ & $12(4-19)$ & $<0.001$ \\
\hline Hospital stay, days & $7(5-11)$ & $7(5-11)$ & $15.5(8-24)$ & $<0.001$ \\
\hline Death, $n$ & $44(5.6 \%)$ & & & \\
\hline
\end{tabular}

$A F$ atrial fibrillation, $A K I$ acute kidney injury, $A M I$ acute myocardial infarction, FFP fresh frozen plasma, ICU intensive care unit, $L C O S$ low cardiac output syndrome, $M V$ mechanical ventilation, $P L T$ platelets, $R B C$ red blood cells, $R R T$ renal replacement therapy

In the overall cardiac surgical population, $C A B G$ is the most frequently performed operation $[5,23]$, and ischemic cardiomyopathy is the most frequent cause of heart failure associated to a reduced EF [24]. Therefore, most cardiac surgery studies have been led on patients with low LVEF undergoing CABG. On the contrary, very few studies have investigated the outcome of patients with low EF undergoing valve surgery [25-27]. As observed by Hamad et al, the prevalence of low EF is as high as $20 \%$ in patients undergoing CABG [2], while the percentage decrease to $10-15 \%$ in patients undergoing valve surgery [25]. To best of our knowledge this is the first study in which a large heterogeneous population with an EF below $40 \%$ undergoing predominantly valve cardiac surgery in a high volume hospital has been investigated. The percentage of patients with pre-operative
EF below $40 \%$ was $11 \%$, with one-third of patients undergoing CABG, and more than $40 \%$ who underwent valve surgery. The vast majority of studies in patients with low EF undergoing CABG has shown a higher perioperative risk and a better survival after myocardial revascularization. In this setting the long-term benefits clearly overcome an increased peri-operative mortality [28].

On the contrary, there are no conclusive data on the perioperative risk of patients with low EF undergoing valve surgery. The assessment of the perioperative risk in this kind of patients is of particular relevance for both the surgical planning and the intra- and postoperative management. Furthermore, the surgical correction of different valve defects has different impact on early postoperative ventricular function and outcome $[29,30]$. 


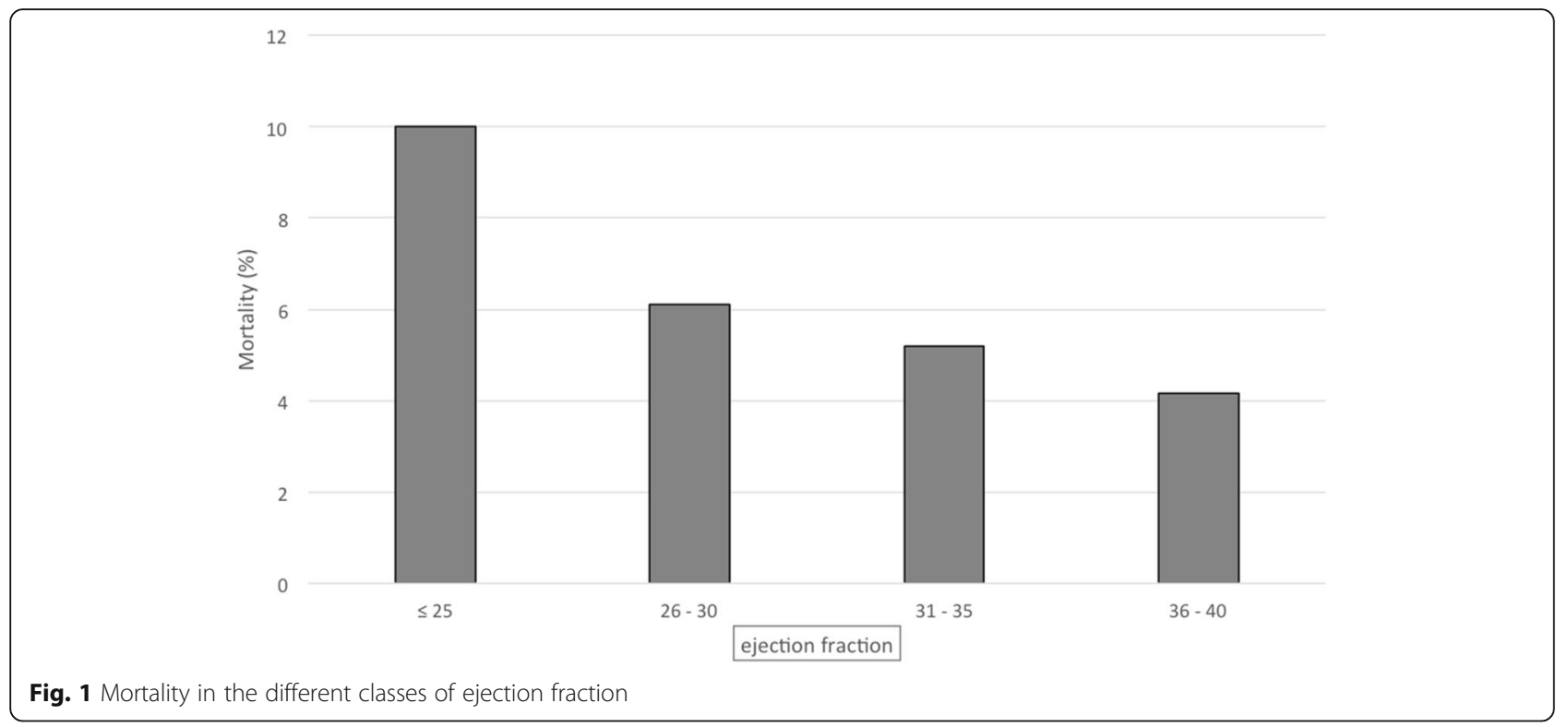

The main result of the present study is that, even in patients with valve disease and impaired EF, cardiac surgery can be performed with acceptable mortality rates Namely, the mortality rate in patients with LVEF $\leq 40 \%$ was $5.6 \%$, while in the subgroup of patients with LVEF $\leq$ $30 \%$ was $7.6 \%$. These findings are slightly better than those reported which range between 3 and $10 \%$ in CABG $[1,2,31]$ and valve surgery [25-27]. In our high surgery volume tertiary care center the mortality rate is better in patients with the highest degree of ventricular dysfunction (LVEF $\leq 30 \%$ ) compared to previous studies, which report a mortality rate as high as $7-10 \%[2,27]$. Our results confirm that, in patients with a reduced LVEF (especially in those with $\mathrm{LVEF} \leq 30 \%$ ), mitral valve surgery is associated with greater risk of an adverse outcome compared to isolated CABG. The prognosis might even be poorer when CABG is associated to mitral valve surgery [5, 32]. In fact, the mitral valve repair and replacement are associated to the highest risk of early postoperative LCOS due to the afterload mismatch, the highest troponin I release [33] and the highest preoperative risk of death [34-37]. Notably, LVEF in the context of moderate-severe and severe mitral regurgitation cannot be relied upon to describe LV systolic function, since part of the left ventricular stroke volume is directed backward (towards the left atrium) and does not contribute to systemic perfusion [38]. Furthermore, the reduction of EF in these patients might often be caused by ischemic cardiomyopathy. In a recent sub-analysis of the Surgical Treatment for Ischemic Heart Failure (STICH) trial, the presence of severe mitral regurgitation was found to be a predictor of 30-day mortality in patients with left ventricular dysfunction undergoing CABG. Interestingly, concomitant mitral valve surgery was associated with better 30-day survival as compared with no mitral valve surgery [31]. Although results from the STICH trial have been challenged by a recent multicenter RCT by Smith and colleagues [39], it should be highlighted that these latter study did not focus on patients with reduced LVEF and mortality was not the primary endpoint in the RCT [39]. Treatment strategies for secondary mitral regurgitation are still a matter of debate, with available studies giving conflicting results [40] and current guidelines providing only weak recommendations

Table $\mathbf{3}$ Independent predictors of mortality (stepwise multivariate analysis)

\begin{tabular}{lllll}
\hline Variable & Odds ratio & $95 \%$ Confidence interval & & \\
\hline LVEF $\leq 40 \%$ & & & & \\
COPD & 3.419 & 1.266 & 9.238 & 0.839 \\
Pre-operative IABP & 3.335 & 1.258 & 64.808 & 0.0154 \\
Pre-operative inotropes & 13.595 & 2.852 & & 0.0011 \\
LVEF $\leq 30 \%$ & & & 25.450 & 0.0041 \\
Pre-operative renal failure & 6.845 & 1.841 & 21.322 & 0.0206 \\
Mitral valve surgery & 5.244 & 1.290 & & \\
\hline
\end{tabular}

COPD chronic obstructive pulmonary disease, IABP intra-aortic balloon pump 
$[41,42]$. Therefore, optimal management of these patients requires both accurate evaluation and risk stratification and a thorough discussion with the patient of the possible risks and benefits.

In patients with $E F<40 \%$, mitral valve surgery, preoperative IABP use and need for inotropes, COPD and chronic kidney disease were identified as independent predictors of mortality. The use of preoperative IABP and inotropes are markers of severity illness rather than primary cause of a worse outcome. Zangrillo et al. have recently shown indeed that IABP improves the outcomes in high risk patients undergoing CABG [43].

It is not surprising that the need of inotropes prior to surgery is the strongest predictors of mortality. Chronic kidney disease and COPD are well known risk factors for both short- and long-term morbidity and mortality after cardiac surgery [44-47]. Our findings clearly show how these conditions acquire an even more considerable relevance in patients who also have a reduced LV function. In the present study the rate of postoperative complications is higher than previously reported in literature. In particular compared with data from recent large studies led in a general cardiac surgical population $[48,49]$, in this high risk population with low EF we found a higher rate of postoperative AKI, AF and LCOS $[36,37]$. On the contrary, we observed a lower rate of myocardial infarction. A possible explanation is that postoperative myocardial infarction after cardiac surgery may be related to inaccurate myocardial protection perioperative hemodynamic instability, a post-operative prothrombotic state complexity of coronary revascularization, surgical technical skills rather than LVEF itself [50].

The following limitations have to be considered: first the retrospective design of the study [51]; second it covers a relatively long period during which both the indications to surgery and the perioperative care may have changed; third the lack of a long-term follow-up. The study is monocentric and a validation group was not available. The performance of the two models is not optimal and they might be further improved in larger multicentric studies; however, the cut-offs for analyses were based on relevant clinical parameters and were chosen according to international guidelines [17]. We are aware that LVEF remains among the strongest predictors of clinical outcome after cardiac surgery, and we cannot exclude that other parameters, that were not taken into consideration in the present study, might play a relevant role. Finally, in some cases, isolated CABG surgery was performed, although mitral valve disease was also present: as we cannot provide the rate of occurrence of this phenomenon, we cannot exclude that it might have influenced our results.

\section{Conclusions}

Moderate-to-severe left ventricular dysfunction is a common finding in the general cardiac surgical population. Patients with reduced LVEF undergoing cardiac surgery have a high-risk of postoperative complications, and higher mortality rates, however the surgery can be performed with relatively low mortality rate. Among the different cardiac surgical procedures patients with low EF undergoing mitral valve surgery show the highest mortality. Accurate preoperative evaluation and risk stratification are of paramount importance in these patients, and careful perioperative management is mandatory.

\section{Additional file}

Additional file 1: Table S1. Baseline and intra-operative characteristics of patients with ejection fraction $\leq 30 \%$ who underwent cardiac surgery: comparisons between survived and dead patients. Table S2. Postoperative complications and outcome data of patients with ejection $\leq 30 \%$ who underwent cardiac surgery: comparisons between survived and dead patients. Table S3. Baseline comorbidities and information of patients undergoing mitral valve surgery. (DOCX $32 \mathrm{~kb}$ )

\section{Abbreviations \\ ACEF: Age-creatinine-ejection fraction; AF: Atrial fibrillation; AKI: Acute kidney injury; CABG: Coronary artery bypass graft; COPD: Chronic obstructive pulmonary disease; EF: Ejection fraction; eGFR: Estimated glomerular filtration rate; IABP: Intra-aortic balloon pump; ICU: Intensive care unit; LCOS: Low cardiac output syndrome; LOS: Length of stay; LV: Left ventricle; LVEF: Left ventricular ejection fraction; RRT: Renal replacement therapy}

Acknowledgements

Maieutics Foundation helped with the statistics.

Funding

The study was supported by departmental funds only.

Availability of data and materials

Data used to perform this study were collected in a large cardiac surgical database which we are planning to use to conduct additional analyses and studies. Therefore, we prefer not to share our raw data at this moment.

\section{Authors' contributions}

Conceived and designed the study: MP AB FM AP GL. Collected data: MP AP MM VD. Analyzed the data: MP FM GM GF GL. Interpreted the data: MP AB FM AP MM VD GM GF AZ GL. Drafted the manuscript: MP AB FM. Critically revised the manuscript: MP AB FM AP MM VD GM GF AZ GL. All authors read and approved the final manuscript.

\section{Competing interests}

The authors declare that they have no competing interests. The corresponding author (Prof G. Landoni) discloses that he was Section Editor for BMC Anesthesiology.

Consent for publication

Not applicable.

Ethics approval and consent to participate

OSR Ethical Committee approved the study on October 31 $1^{\text {st }}, 2013$ (38 AN CCH 31-10-2013). No specific written consent was obtained for this retrospective observational study since all patients' data were anonymized and de-identified prior to analysis. However, all patients signed a written consent for the use of their data for scientific purposes. 


\section{Author details}

'Department of Anesthesia and Intensive Care, IRCCS San Raffaele Scientific Institute, Via Olgettina 60, 20132 Milan, Italy. ${ }^{2}$ Cardiac Anesthesia and Intensive Care Unit, Monaldi Hospital A.O.R.N. "Dei Colli", Naples, Italy. ${ }^{3}$ Department of Medical Sciences "M. Aresu", University of Cagliari, Cagliari, Italy. "Vita-Salute San Raffaele University, Milan, Italy.

\section{Received: 24 May 2016 Accepted: 12 October 2016}

\section{Published online: 18 October 2016}

\section{References}

1. Topkara VK, Cheema FH, Kesavaramanujam S, Mercando ML, Cheema AF, Namerow PB, et al. Coronary artery bypass grafting in patients with low ejection fraction. Circulation. 2005;112(9 Suppl):1344-50. doi:10.1161/ CIRCULATIONAHA.104.526277.

2. Hamad MA, van Straten AH, Schönberger JP, ter Woorst JF, de Wolf AM, Martens EJ, et al. Preoperative ejection fraction as a predictor of survival after coronary artery bypass grafting: comparison with a matched general population. J Cardiothorac Surg. 2010;5:29. doi:10.1186/1749-8090-5-29.

3. Heijmans JH, Maessen JG, Roekaerts PM. Risk stratification for adverse outcome in cardiac surgery. Eur J Anaesthesiol. 2003;20:515-27. doi:10.1097/ 00003643-200307000-00002.

4. Parsonnet $\mathrm{V}$, Dean $\mathrm{D}$, Bernstein $\mathrm{AD}$. A method of uniform stratification of risk for evaluating the results of surgery in acquired adult heart disease. Circulation. 1989;79(6 Pt 2):13-12.

5. Nashef SA, Roques F, Sharples LD, Nilsson J, Smith C, Goldstone AR, et al. EuroSCORE II. Eur J Cardiothorac Surg. 2012;41:734-44. doi:10.1093/ejcts/ ezs043. discussion 744-5.

6. Shahian DM, O'Brien SM, Filardo G, Ferraris VA, Haan CK, Rich JB, et al. The Society of Thoracic Surgeons 2008 cardiac surgery risk models: part 1coronary artery bypass grafting surgery. Ann Thorac Surg. 2009;88(1 Suppl):S222. doi:10.1016/j.athoracsur.2009.05.053.

7. O'Connor GT, Plume SK, Olmstead EM, Coffin LH, Morton JR, Maloney CT, et al. Multivariate prediction of in-hospital mortality associated with coronary artery bypass graft surgery. Northern New England Cardiovascular Disease Study Group. Circulation. 1992;85:2110-8. doi:10.1161/01.CIR.85.6.2110.

8. Ranucci M, Castelvecchio S, Menicanti L, Frigiola A, Pelissero G. Risk of assessing mortality risk in elective cardiac operations: age, creatinine, ejection fraction, and the law of parsimony. Circulation. 2009;119:3053-61. doi:10.1161/CIRCULATIONAHA.108.842393.

9. Thakar CV, Arrigain S, Worley S, Yared JP, Paganini EP. A clinical score to predict acute renal failure after cardiac surgery. J Am Soc Nephrol. 2005;16:162-8. doi:10.1681/ASN.2004040331.

10. Allou N, Bronchard R, Guglielminotti J, Dilly MP, Provenchere S, Lucet JC, et al. Risk factors for postoperative pneumonia after cardiac surgery and development of a preoperative risk score. Crit Care Med. 2014;42:1150-6. doi:10.1097/CCM.0000000000000143.

11. Royster RL, Butterworth 4th JF, Prough DS, Johnston WE, Thomas JL, Hogan PE, et al. Preoperative and intraoperative predictors of inotropic support and longterm outcome in patients having coronary artery bypass grafting. Anesth Analg. 1991;72:729-36.

12. Butterworth 4th JF, Legault C, Royster RL, Hammon Jr JW. Factors that predict the use of positive inotropic drug support after cardiac valve surgery. Anesth Analg. 1998;86:461-7. doi:10.1213/00000539-199803000-00002.

13. Bove T, Calabrò MG, Landoni G, Aletti G, Marino G, Crescenzi G, et al. The incidence and risk of acute renal failure after cardiac surgery. J Cardiothorac Vasc Anesth. 2004;18:442-5. doi:10.1053/j.jvca.2004.05.021.

14. Landoni G, Bove T, Crivellari M, Poli D, Fochi O, Marchetti C, et al. Acute renal failure after isolated CABG surgery: 6 years of experience. Minerva Anestesiol. 2007;73:559-65.

15. Mariscalco G, Biancari F, Zanobini M, Cottini M, Piffaretti G, Saccocci M, et al. Bedside tool for predicting the risk of postoperative atrial fibrillation after cardiac surgery: the POAF score. J Am Heart Assoc. 2014;3:e000752. doi:10.1161/JAHA.113.000752

16. Birkmeyer JD, Siewers AE, Finlayson EV, Stukel TA, Lucas FL, Batista I, et al. Hospital volume and surgical mortality in the United States. N Engl J Med. 2002:346:1128-37. doi:10.1056/NEJMsa012337.

17. Lang RM, Badano LP, Mor-Avi V, Afilalo J, Armstrong A, Ernande L, et al. Recommendations for cardiac chamber quantification by echocardiography in adults: an update from the American Society of Echocardiography and the European Association of Cardiovascular Imaging. J Am Soc Echocardiogr. 2015;28:1-39.e14. doi:10.1016/j.echo.2014.10.003.

18. Thygesen K, Alpert JS, White HD, Joint ESC/ACCF/AHAMWHF Task Force for the Redefinition of Myocardial Infarction. Universal definition of myocardial infarction. Eur Heart J. 2007;28:2525-38. doi:10.1093/eurheartj/ehm355.

19. Prondzinsky R, Unverzagt $\mathrm{S}$, Russ $\mathrm{M}$, Lemm H, Swyter $\mathrm{M}$, Wegener $\mathrm{N}$, et al. Hemodynamic effects of intra-aortic balloon counterpulsation in patients with acute myocardial infarction complicated by cardiogenic shock: the prospective, randomized IABP shock trial. Shock. 2012;37:378-84. doi:10.1097/SHK.0b013e31824a67af.

20. Bellomo R, Ronco C, Kellum JA, Mehta RL, Palevsky P. Acute renal failure - definition, outcome measures, animal models, fluid therapy and information technology needs: the Second International Consensus Conference of the Acute Dialysis Quality Initiative (ADQI) Group. Crit Care. 2004:8:R204-12. doi:10.1186/cc2872.

21. Cockcroft DW, Gault MH. Prediction of creatinine clearance from serum creatinine. Nephron. 1976:16:31-41. doi:10.1159/000180580.

22. Ranucci M, Castelvecchio S, Conte M, Megliola G, Speziale G, Fiore F, et al. The easier, the better: age, creatinine, ejection fraction score for operative mortality risk stratification in a series of 29,659 patients undergoing elective cardiac surgery. J Thorac Cardiovasc Surg. 2011;142:581-6. doi:10.1016/j.jtcvs. 2010.11.064.

23. O'Brien SM, Shahian DM, Filardo G, Ferraris VA, Haan CK, Rich JB, et al. The Society of Thoracic Surgeons 2008 cardiac surgery risk models: part 2 isolated valve surgery. Ann Thorac Surg. 2009;88(1 Suppl):S23-42. doi:10.1016/j. athoracsur.2009.05.056

24. McMurray JJ, Adamopoulos S, Anker SD, Auricchio A, Böhm M, Dickstein K, et al. ESC Guidelines for the diagnosis and treatment of acute and chronic heart failure 2012: The Task Force for the Diagnosis and Treatment of Acute and Chronic Heart Failure 2012 of the European Society of Cardiology. Developed in collaboration with the Heart Failure Association (HFA) of the ESC. Eur Heart J. 2012;33:1787-847. doi:10.1093/eurheartj/ehs104.

25. Halkos ME, Chen EP, Sarin EL, Kilgo P, Thourani VH, Lattouf OM, et al. Aortic valve replacement for aortic stenosis in patients with left ventricular dysfunction. Ann Thorac Surg. 2009;88:746-51. doi:10.1016/j.athoracsur.2009.05.078.

26. Maltais S, Schaff HV, Daly RC, Suri RM, Dearani JA, Sundt 3rd TM, et al. Mitral regurgitation surgery in patients with ischemic cardiomyopathy and ischemic mitral regurgitation: factors that influence survival. J Thorac Cardiovasc Surg. 2011;142:995-1001. doi:10.1016/j.jtcvs.2011.07.044.

27. Parker JA, Kennes LN, Ruckert J, Dahm M, Vahl CF. Outcome after mitral valve operations with depressed left ventricular function. Asian Cardiovasc Thorac Ann 2012;20:292-8. doi:10.1177/0218492312437385.

28. Velazquez EJ, Lee KL, Jones RH, Al-Khalidi HR, Hill JA, Panza JA, et al. Coronary-artery bypass surgery in patients with ischemic cardiomyopathy. N Engl J Med. 2016:374:1511-20 doi:10.1056/NEJMoa1602001.

29. Harpole Jr DH, Gall Jr SA, Wolfe WG, Rankin JS, Jones RH. Effects of valve replacement on ventricular mechanics in mitral regurgitation and aortic stenosis. Ann Thorac Surg. 1996;62:756-61. doi:10.1016/ S0003-4975(96)00378-5.

30. Duncan AE, Sarwar S, Kateby Kashy B, Sonny A, Sale S, Alfirevic A, et al. Early Left and Right Ventricular Response to Aortic Valve Replacement. Anesth Analg. 2015. doi: 10.1213/ANE.0000000000001108. In press.

31. Wrobel K, Stevens SR, Jones RH, Selzman CH, Lamy A, Beaver TM, et al. Influence of baseline characteristics, operative conduct, and postoperative course on 30-day outcomes of coronary artery bypass grafting among patients with left ventricular dysfunction: results from the Surgical Treatment for Ischemic Heart Failure (STICH) trial. Circulation. 2015;132:720-30. doi:10. 1161/CIRCULATIONAHA.114.014932

32. Shahian DM, O'Brien SM, Filardo G, Ferraris VA, Haan CK, Rich JB, et al. The Society of Thoracic Surgeons 2008 cardiac surgery risk models: part 3-valve plus coronary artery bypass grafting surgery. Ann Thorac Surg. 2009:88(1 Suppl):S43-62. doi:10.1016/j.athoracsur.2009.05.055.

33. Monaco F, Landoni G, Biselli C, De Luca M, Frau G, Bignami E, et al. Predictors of cardiac troponin release after mitral valve surgery. J Cardiothorac Vasc Anesth. 2010;24:931-8. doi:10.1053/j.jvca.2010.06.029.

34. Melisurgo G, Ajello S, Pappalardo F, Guidotti A, Agricola E, Kawaguchi M, et al. Afterload mismatch after MitraClip insertion for functional mitral regurgitation. Am J Cardiol. 2014;113:1844-50. doi:10.1016/j.amjcard.2014.03.015.

35. Ross Jr J. Afterload mismatch in aortic and mitral valve disease: implications for surgical therapy. J Am Coll Cardiol. 1985;5:811-26. doi:10.1016/S0735-1097(85)80418-6. 
36. Maganti M, Badiwala M, Sheikh A, Scully H, Feindel C, David TE, et al. Predictors of low cardiac output syndrome after isolated mitral valve surgery. J Thorac Cardiovasc Surg. 2010;140:790-6. doi:10.1016/j.jtcvs.2009.11.022.

37. Algarni KD, Maganti M, Yau TM. Predictors of low cardiac output syndrome after isolated coronary artery bypass surgery: trends over 20 years. Ann Thorac Surg. 2011;92:1678-84. doi:10.1016/j.athoracsur.2011.06.017.

38. Kamperidis V, Marsan NA, Delgado V, Bax JJ. Left ventricular systolic function assessment in secondary mitral regurgitation: left ventricular ejection fraction vs. speckle tracking global longitudinal strain. Eur Heart J. 2016;37: 811-6. doi:10.1093/eurheartj/ehv680.

39. Smith PK, Puskas JD, Ascheim DD, Voisine P, Gelijns AC, Moskowitz AJ, et al. Surgical treatment of moderate ischemic mitral regurgitation. N Engl J Med. 2014;371:2178-88. doi:10.1056/NEJMoa1410490.

40. Bonow RO. The saga continues: does mitral valve repair improve survival in secondary mitral regurgitation? JACC Cardiovasc Interv. 2014;7:882-4. doi:10.1016/j.jin.2014.05.009.

41. Vahanian A, Alfieri O, Andreotti F, Antunes MJ, Barón-Esquivias G, Baumgartner H, et al. Guidelines on the management of valvular heart disease (version 2012). Eur Heart J. 2012;33:2451-96. doi:10.1093/eurheartj/ehs109.

42. Windecker S, Kolh P, Alfonso F, Collet JP, Cremer J, Falk V, et al. 2014 ESC/EACTS Guidelines on myocardial revascularization: The Task Force on Myocardial Revascularization of the European Society of Cardiology (ESC) and the European Association for Cardio-Thoracic Surgery (EACTS). Developed with the special contribution of the European Association of Percutaneous Cardiovascular Interventions (EAPCI). Eur Heart J. 2014;35:2541-619. doi:10.1093/eurheartj/ehu278.

43. Zangrillo A, Pappalardo F, Dossi R, Di Prima AL, Sassone ME, Greco T, et al. Preoperative intra-aortic balloon pump to reduce mortality in coronary artery bypass graft: a meta-analysis of randomized controlled trials. Crit Care. 2015;19:10. doi:10.1186/s13054-014-0728-1.

44. Saleh HZ, Mohan K, Shaw M, Al-Rawi O, Elsayed H, Walshaw M, et al. Impact of chronic obstructive pulmonary disease severity on surgical outcomes in patients undergoing non-emergent coronary artery bypass grafting. Eur J Cardiothorac Surg. 2012;42:108-13. doi:10.1093/ejcts/ezr271. discussion 113.

45. Angouras DC, Anagnostopoulos CE, Chamogeorgakis TP, Rokkas CK, Swistel $\mathrm{DG}$, Connery CP, et al. Postoperative and long-term outcome of patients with chronic obstructive pulmonary disease undergoing coronary artery bypass grafting. Ann Thorac Surg. 2010;89:1112-8. doi:10.1016/j.athoracsur. 2010.01.009.

46. Hedley AJ, Roberts MA, Hayward PA, Shaw M, Matalanis G, Buxton BF, et al. Impact of chronic kidney disease on patient outcome following cardiac surgery. Heart Lung Circ. 2010;19:453-9. doi:10.1016/j.hlc.2010.03.005.

47. Cooper WA, O'Brien SM, Thourani VH, Guyton RA, Bridges CR, Szczech LA, et al. Impact of renal dysfunction on outcomes of coronary artery bypass surgeny: results from the Society of Thoracic Surgeons National Adult Cardiac Database. Circulation. 2006;113:1063-70. doi:10.1161/CIRCULATIONAHA.105. 580084

48. Bove T, Zangrillo A, Guarracino F, Alvaro G, Persi B, Maglioni E, et al. Effect of fenoldopam on use of renal replacement therapy among patients with acute kidney injury after cardiac surgery: a randomized clinical trial. JAMA. 2014;312:2244-53. doi:10.1001/jama.2014.13573.

49. Meybohm P, Bein B, Brosteanu O, Cremer J, Gruenewald M, Stoppe C, et al. A multicenter trial of remote ischemic preconditioning for heart surgery. N Engl J Med. 2015;373:1397-407. doi:10.1056/NEJMoa1413579.

50. Thygesen $\mathrm{K}$, Alpert JS, Jaffe AS, Simoons ML, Chaitman BR, White HD, et al. Third universal definition of myocardial infarction. Eur Heart J. 2012;33:2551-67. doi:10.1093/eurheartj/ehs184.

51. Biondi-Zoccai G, Landoni G, Modena MG. A journey into clinical evidence: from case reports to mixed treatment comparisons. HSR Proc Intensive Care Cardiovasc Anesth. 2011;3:93-6.

\section{Submit your next manuscript to BioMed Central and we will help you at every step:}

- We accept pre-submission inquiries

- Our selector tool helps you to find the most relevant journal

- We provide round the clock customer support

- Convenient online submission

- Thorough peer review

- Inclusion in PubMed and all major indexing services

- Maximum visibility for your research

Submit your manuscript at www.biomedcentral.com/submit
Biomed Central 